\title{
Tumour necrosis factor $\alpha$ secretion in leporine endotoxaemia: role of the liver and effects of hepatic ischaemia
}

\author{
I L R Badger, P Townsend, J A C Buckels
}

\begin{abstract}
A leporine model to investigate tumour necrosis factor $\alpha$ (TNF $\alpha$ ) secretion after peripheral vein or mesenteric vein lipopolysaccharide injection was devised. Mesenteric vein injection provoked lower arterial concentrations after 90 minutes (median (range), 2.81, (0.75-11.96) $\mathrm{ng} / \mathrm{ml})$ than peripheral vein injection $(7 \cdot 00(4 \cdot 27-14.95) \mathrm{ng} /$ $\mathrm{ml}(\mathrm{p}<0.05))$. Mesenteric vein injection after 10 minutes' warm hepatic ischaemia, which impairs hepatic clearance, provoked higher median arterial TNF $\alpha$ values at 90 minutes $(7.98(2.85-21.48) \mathrm{ng} / \mathrm{ml})$ than in normal animals $(p<0.05)$. Portal vein endotoxaemia induced less TNF $\alpha$ production than systemic endotoxaemia unless hepatic clearance was impaired, thus the major source of TNF $\alpha$ in systemic endotoxaemia is probably extrahepatic.
\end{abstract}

The liver is the major organ of clearance of circulating bacterial endotoxin. It normally clears $40 \%$ of endotoxin injected into a peripheral vein and over $75 \%$ of a dose injected into the portal vein. ${ }^{12}$ The mortality for peripheral vein injection is significantly greater than that for portal vein injection. ${ }^{23}$ The initial uptake of endotoxin in the liver is by the Kupffer cells, which form the largest fixed population of macrophages in the body. ${ }^{+}$Hepatic clearance is reduced in a number of hepatobiliary diseases such as cirrhosis and obstructive jaundice, with a compensatory increase in pulmonary and splenic uptake. $^{5-7}$ In these diseases there is a high incidence of portal vein and systemic endotoxaemia and an increased incidence of bacterial infection and of renal and other organ failure, effects that are attributed to endotoxaemia. ${ }^{8-11}$ The mortality from Gram negative bacterial sepsis is increased if Kupffer cell clearance is subnormal. ${ }^{12}$ The central mediator of the toxic and lethal effects of endotoxaemia is tumour necrosis factor $\alpha$ (TNF $\alpha)$, circulating concentrations of which correlate with mortality in sepsis and endotoxaemia. ${ }^{13-15}$ TNF $\alpha$ secretion after systemic and mesenteric vein endotoxin injection has not been examined, and the effects of reduced hepatic clearance are unknown.

We have used a leporine model to determine the patterns of TNF $\alpha$ secretion after peripheral vein and mesenteric vein injection of purified endotoxin lipopolysaccharide, and the effects of a short period of warm ischaemia, an insult that has been shown to reduce hepatic clearance. ${ }^{16}$

\section{Methods}

Fifty four healthy female New Zealand white rabbits, weighing from 3.0 to $4.5 \mathrm{~kg}$ were studied. They were anaesthetised with $2 \mathrm{mg} / \mathrm{kg}$ midazolam (Roche, Welwyn Garden City) and $0.3 \mathrm{ml} / \mathrm{kg}$ Hypnorm (Jannsen, Oxford) by intramuscular injection, intubated, and ventilated. Cannulae were inserted aseptically into the right external jugular vein and femoral artery. A 6 FG umbilical catheter was introduced via the right femoral vein and the tip was advanced to the level of the intra-abdominal suprahepatic inferior vena cava, the position was checked at laparotomy. Saline was infused into the jugular vein to replace blood withdrawn and to maintain baseline mean arterial pressures. The arterial line was connected to a pressure monitor (Medex, Rossendale) flushed with heparinised saline $(1 \mathrm{U} / \mathrm{ml})$; the inferior vena cava catheter was heparin locked with $2 \mathrm{ml}$ of the same solution.

The animals received $2.5 \mu \mathrm{g} / \mathrm{kg}$ of Escherichia coli 0111:B4 lipopolysaccharide (Sigma, Poole) or $5 \mathrm{ml}$ endotoxin free saline. Three groups of 18 animals were studied, in each of which 12 animals received endotoxin and six received endotoxin free saline. The groups were: (1) marginal ear vein injection (MEVI); (2) mesenteric vein injection (MVI); and (3) mesenteric vein injection after 10 minutes occlusion of the portal vein and hepatic artery by a vascular clamp (ISCH).

Blood samples were taken at baseline and at 5 , 30,60 , and 90 minutes after injection. Blood was taken from the arterial line and inferior vena cava catheter at each time point, discarding the first $2 \mathrm{ml}$ dead space volume, from the portal vein by direct venepuncture before and 90 minutes after injection, and from the infrahepatic inferior vena cava at 90 minutes by direct venepuncture. Blood specimens were mixed with endotoxin free heparin (Sigma, Poole) (60 U USP/ml blood) on melting ice, then centrifuged at $2400 \mathrm{~g}$ for five minutes. Plasma was aliquoted into endotoxin free Falcon polypropylene tubes (BectonDickenson, Dublin), and stored at $-70^{\circ} \mathrm{C}$.

TNF $\alpha$ assays were performed within 48 hours using the L929 cell assay described by Flick and Gifford, ${ }^{17}$ with some modifications. In brief, 
TABLE I Median (range) plasma tumour necrosis factor $\alpha$ concentrations $(n g / m l)$ in animals receiving lipopolysaccharide in group 1 (peripheral lipopolysaccharide and group 2 (mesenteric lipopolysaccharide $)(n=12)$, by site and timepoint

\begin{tabular}{|c|c|c|c|}
\hline & Group 1 & Group 2 & p value \\
\hline \multicolumn{4}{|l|}{ Baseline: } \\
\hline Portal & $0.05(0-0.21)$ & $0.07(0-0.22)$ & NS \\
\hline Arterial & $0.03(0-0.12)$ & $0.03(0-0.13)$ & NS \\
\hline \multirow{2}{*}{\multicolumn{4}{|c|}{30 minutes postinjection: }} \\
\hline & & & \\
\hline Arterial & $0.31(0.16-0.63)^{\star}$ & $0 \cdot 46(0 \cdot 18-1 \cdot 73)$ & NS \\
\hline Suprahepatic IVC & $0.49(0.12-0.91)$ & $0.58(0.20-1.85)$ & NS \\
\hline \multicolumn{4}{|l|}{60 minutes postinjection: } \\
\hline Arterial & $6 \cdot 45(4 \cdot 03-11 \cdot 75)$ & $8 \cdot 25(2 \cdot 38-20 \cdot 22)$ & NS \\
\hline Suprahepatic IVC & $9 \cdot 12(4.95-17 \cdot 79)$ & $10 \cdot 49(4 \cdot 22-22 \cdot 68)$ & NS \\
\hline \multicolumn{4}{|l|}{90 minutes postinjection: } \\
\hline Portal & $9 \cdot 59(4 \cdot 68-19 \cdot 15)$ & $2.93(1.27-18 \cdot 87)$ & $<0.05$ \\
\hline Arterial & $7 \cdot 00(4 \cdot 27-14 \cdot 95)^{\star}$ & $2.81(0.75-11.96)$ & $<0.05$ \\
\hline Suprahepatic IVC & $10.58(5 \cdot 76-16.69)$ & $4.00(0.97-17.61)$ & $<0.05$ \\
\hline Infrahepatic IVC & $6.82(4.04-11.08)$ & $2.89(0.77-8.04)$ & $<0.05$ \\
\hline \multicolumn{4}{|l|}{ Peak values: } \\
\hline Arterial & $9 \cdot 25(4 \cdot 79-14 \cdot 95)$ & $8 \cdot 25(2 \cdot 38-20 \cdot 22)$ & NS \\
\hline Suprahepatic IVC & $10 \cdot 85(7 \cdot 59-17 \cdot 79)$ & $10 \cdot 49(4 \cdot 22-22 \cdot 68)$ & NS \\
\hline
\end{tabular}

IVC $=$ inferior vena cava

$\star$ In Group 1 arterial $v$ suprahepatic IVC $\mathrm{p}<0.05$ at 30 minutes. Arterial $v$ suprahepatic IVC $\mathrm{p}<0.05$ and infrahepatic IVC $v$ suprahepatic IVC $\mathrm{p}<0.05$ at 90 minutes.

confluent monolayers of L929 cells, seeded in flat bottomed, 96 well microtitre plates at a density of $2.5 \times 10^{4}$ cells per well, were exposed to serial dilutions of plasma samples or human recombinant NISBC TNF $\alpha$ standard (Celltech, Slough) in $100 \mu \mathrm{l} /$ well of Dulbecco's modification of Eagle's medium supplemented with 5\% fetal calf serum, $2 \mathrm{mmol} / \mathrm{l}$ glutamine, $250 \mathrm{U} / \mathrm{m}$ penicillin, $125 \mu \mathrm{g} / \mathrm{ml}$ streptomycin, and $1 \mu \mathrm{g} / \mathrm{ml}$ of actinomycin D. After 20 hours' incubation at $37^{\circ} \mathrm{C}$ the medium was discarded, the wells washed with phosphate buffered saline (PBS), and $100 \mu \mathrm{l}$ of $0 \cdot 25 \%$ rose bengal (Sigma) solution in normal saline was added for 10 minutes. The cells were washed twice with PBS, and $200 \mu \mathrm{l}$ of $50 \%$ ethanol were added to lyse the cells. The optical density was measured at $570 \mathrm{~nm}$ on a Titertek Multiskan plate reader after 30 minutes. Results were calculated according to the method of Flick and Gifford ${ }^{17}$ and are expressed in $\mathrm{ng} / \mathrm{ml}$. The coefficient of variability of this assay in our laboratory is $10 \%$. The mean (SD) recovery of the TNF $\alpha$ standard from leporine plasma, over a dose range of $0 \cdot 1$ to $10 \mathrm{ng} / \mathrm{ml}$ was $101(7) \%$, range $82-116 \%$.

Endotoxin assays were performed on arterial blood specimens taken at baseline, and at five to 30 minutes after injection, and on portal vein

TABLE II Median (range) plasma tumour necrosis factor $\alpha$ concentrations $(\mathrm{ng} / \mathrm{ml}$ ) in animals receiving lipopolysaccharide in group 3 (mesenteric lipopolysaccharide after 10 minutes warm ischaemia) and group 2 (mesenteric lipopolysaccharide) $(n=12)$

\begin{tabular}{|c|c|c|c|}
\hline & Group 3 & Group 2 & p value \\
\hline \multicolumn{4}{|l|}{ Baseline: } \\
\hline Portal & $0.07(0.02-0.18)$ & $0.07(0-0.22)$ & NS \\
\hline Arterial & $0.08(0-0 \cdot 18)$ & $0.03(0-0.13)$ & NS \\
\hline Suprahepatic IVC & $0.08(0.04-0.20)$ & $0.08(0-0.13)$ & NS \\
\hline \multicolumn{4}{|l|}{30 minutes postinjection: } \\
\hline Arterial & $0 \cdot 61(0 \cdot 26-1 \cdot 76)$ & $0 \cdot 46(0 \cdot 18-1 \cdot 73)$ & NS \\
\hline Suprahepatic IVC & $1.03(0 \cdot 23-1 \cdot 88)$ & $0.58(0.20-1.85)$ & NS \\
\hline \multicolumn{4}{|l|}{60 minutes postinjection: } \\
\hline Arterial & $6 \cdot 49(3 \cdot 59-15 \cdot 29)$ & $8 \cdot 25(2 \cdot 38-20 \cdot 22)$ & NS \\
\hline Suprahepatic IVC & $8.76(3.05-20.51)$ & $10 \cdot 49(4 \cdot 22-22 \cdot 68)$ & NS \\
\hline \multicolumn{4}{|l|}{90 minutes postinjection: } \\
\hline Portal & $6 \cdot 38(3 \cdot 42-20 \cdot 15)$ & $2.93(1 \cdot 27-18 \cdot 87)$ & $<0.05$ \\
\hline Arterial & $7 \cdot 98(2 \cdot 85-21 \cdot 48)$ & $2.81(0.75-11.96)$ & $<0.05$ \\
\hline Suprahepatic IVC & $8.66(4 \cdot 51-27 \cdot 67)$ & $4.00(0.97-17.61)$ & $<0.05$ \\
\hline Infrahepatic IVC & $6 \cdot 82(2 \cdot 21-22 \cdot 49)$ & $2 \cdot 89(0.77-8.04)$ & $<0.05$ \\
\hline \multicolumn{4}{|l|}{ Peak values: } \\
\hline Arterial & $8 \cdot 48(4 \cdot 79-21 \cdot 48)$ & $8 \cdot 25(2 \cdot 38-20 \cdot 22)$ & NS \\
\hline Suprahepatic IVC & $9 \cdot 73(7 \cdot 59-27 \cdot 76)$ & $10 \cdot 49(4 \cdot 22-22 \cdot 68)$ & NS \\
\hline
\end{tabular}

IVC $=$ inferior vena cava blood at baseline and 90 minutes, using the Coatest quantitative photometric Limulus amoebocyte lysate assay (KabiVitrum, Middlesex). In brief plasma samples were diluted one in 10 with endotoxin free water and heated in a water bath at $75^{\circ} \mathrm{C}$ for five minutes. Endotoxin standards were prepared with $E$ coli 0111:B4 lipopolysaccharide, diluted in 10\% solutions of endotoxin free leporine plasma, over the range $0-100 \mathrm{pg} / \mathrm{ml}$. Assays were performed in duplicate in flat bottomed 96 well microtitre plates. Fifty $\mu \mathrm{l}$ of sample or standard were added to the wells, and the plate was incubated at $37^{\circ} \mathrm{C}$ for five minutes. Fifty $\mu \mathrm{l}$ of Limulus amoebocyte lysate were added, and the plate was incubated at $37^{\circ} \mathrm{C}$ for 25 minutes. Fifty $\mu$ l each of $2 \mathrm{mmol} / \mathrm{l}$ chromogenic substrate (Ac-Ile-GluGly-Arg-pNA HCL) solution and $50 \mathrm{mmol} / \mathrm{l}$ Tris were added to the wells and the plate was incubated for five minutes. The reaction was arrested by adding $100 \mu \mathrm{l}$ acetic acid, and the absorbance was measured at $405 \mathrm{~nm}$. Results were calculated according to the manufacturer's instructions: samples containing over $100 \mathrm{pg} / \mathrm{ml}$ were further diluted until the endotoxin concentration was within the assay range (17$100 \mathrm{pg} / \mathrm{ml}$ ).

Results are given as median (range). Statistical analysis was by the Mann-Whitney U test.

\section{Results}

TNFO

Results for the animals receiving lipopolysaccharide in groups 1 (MEVI) and 2 (MVI) are shown in Table I. Control animals in both groups had plasma TNF $\alpha$ values less than $0.2 \mathrm{ng} / \mathrm{ml}$ throughout the experiment. In group 1 (MEVI), arterial $\mathrm{TNF} \alpha$ concentrations peaked at 60 minutes in six animals and at 90 minutes in six animals. In group 2 (MVI) arterial TNFo concentrations peaked at 60 minutes in all 12 animals, and were of comparable magnitude to those in group 1 (MEVI). Median TNF $\alpha$ values at 30 and 60 minutes from all sample sites were comparable in the two groups, but by 90 minutes median plasma TNF $\alpha$ concentrations from all sample sites were significantly lower in group 2 (MVI) animals compared with group 1 (MEVI), indicating a lower total output of TNF $\alpha$.

In a group 1 (MEVI) median arterial values were significantly lower than suprahepatic inferior vena cava values at 30 minutes $(p<0.05)$ and at 90 minutes $(\mathrm{p}<0.05)$. At 90 minutes the median suprahepatic inferior vena cava plasma TNF $\alpha$ value was significantly higher than the median infrahepatic inferior vena cava $T N F \alpha$, but median portal vein concentrations were intermediate in value between arterial and suprahepatic inferior vena cava concentrations and not significantly different to either of them. This suggests a source of $T N F \alpha$ in the splanchnic territory drained by the hepatic vein.

Results for group 3 (ISCH) animals receiving lipopolysaccharide are shown in Table II and compared with those from group 2 (MVI). Results for control animals in these groups are shown in Table III. Group 3 (ISCH) animals given lipopolysaccharide showed a similar 
TABLE III Median (range) plasma tumour necrosis factor $\alpha$ concentrations $(\mathrm{ng} / \mathrm{ml}$ ) in animals receiving saline in group 3 (mesenteric lipopolysaccharide after 10 minutes warm ischaemia) and group 2 (mesenteric lipopolysaccharide) $(n=6)$

\begin{tabular}{|c|c|c|c|}
\hline & Group 3 & Group 2 & pvalue \\
\hline \multicolumn{4}{|l|}{ Baseline: } \\
\hline Portal & $0.06(0.01-0 \cdot 15)$ & $0.05(0-0.08)$ & NS \\
\hline Arterial & $0.07(0.04-0.13)$ & $0 \cdot 10(0-0 \cdot 12)$ & NS \\
\hline Suprahepatic IVC & $0.07(0.04-0.13)$ & $0.09(0.05-0.11)$ & NS \\
\hline \multicolumn{4}{|l|}{30 minutes postinjection: } \\
\hline Arterial & $0.04(0-0 \cdot 13)$ & $0.08(0-0 \cdot 11)$ & NS \\
\hline Suprahepatic IVC & $0.06(0-0.11)$ & $0.08(0-0.13)$ & NS \\
\hline \multicolumn{4}{|l|}{60 minutes postinjection: } \\
\hline Arterial & $0.03(0-0.06)$ & $0.08(0-0.09)$ & NS \\
\hline Suprahepatic IVC & $0.05(0-0.06)$ & $0.06(0-0.08)$ & NS \\
\hline \multicolumn{4}{|l|}{90 minutes postinjection: } \\
\hline Portal & $0.13(0.02-0.15)$ & $0.07(0-0.11)$ & NS \\
\hline Arterial & $0.11(0.01-0.13)$ & $0.07(0-0.08)$ & NS \\
\hline Suprahepatic IVC & $0.03(0-0 \cdot 11)$ & $0.08(0-0.09)$ & NS \\
\hline
\end{tabular}

IVC $=$ inferior vena cava are released during endotoxaemia, including interleukin-1 (IL-1) and interleukin-6 (IL-6). IL-1 is not detected consistently, and circulating concentrations do not correlate with outcome in humans. ${ }^{1518}$ IL-6 values do correlate with outcome in human sepsis, but peak circulating concentrations are seen some hours after TNF $\alpha$ values have peaked and fallen. ${ }^{15} \mathrm{TNF} \alpha$ is both an accurate prognostic factor and an early circulating marker of severe sepsis and endotoxaemia. The L929 cell assay for TNF $\alpha$ is sensitive but cannot distinguish between TNF $\alpha$ and TNF $\beta$; however, TNF $\beta$ is not secreted in endotoxaemia. ${ }^{15} 1720$

The dose of lipopolysaccharide used in this study $(2 \cdot 5 \mu \mathrm{g} / \mathrm{kg})$ was found in pilot studies to be the lowest dose capable of producing maximal $\mathrm{TNF} \alpha$ production after peripheral injection, without causing significant haemodynamic disturbance over the duration of the experiment. Mesenteric vein injection of this dose provoked a significantly lower total TNF $\alpha$ output than peripheral vein injection, which could explain the lower observed mortality from portal vein endotoxaemia and has not been described previously. This finding further suggests that the liver is not the major source of TNF $\alpha$ in endotoxaemia.

The individual TNF $\alpha$ values show a wide range within the experimental groups, as has been reported previously in this species. ${ }^{21}$ This may explain the differences in individual sensitivity to the lethal and toxic effects of lipopolysaccharide. Differences in plasma TNF $\alpha$ concentrations in the three groups are seen only at 90 minutes, with no statistically significant differences apparent at 30 or 60 minutes. This is explicable by the kinetics of $\mathrm{TNF} \alpha$ production by different macrophage populations. Callery et al $^{22}$ have shown in vitro that lipopolysaccharide stimulated rat Kupffer cells produce less TNF $\alpha$ than alveolar macrophages from the same animals, and do so over much shorter periods. If endotoxin clearance is principally hepatic, as it is after portal vein administration, ${ }^{12}$ one would expect to see an earlier peak and a more rapid decline in circulating values than if clearance were principally extrahepatic.

Peripheral vein endotoxaemia led to significantly higher $\mathrm{TNF} \alpha$ concentrations in suprahepatic inferior vena cava blood than in arterial blood. This suggests a splanchnic source, and supports the findings reported by Fong et al of higher hepatic vein than peripheral arterial TNF $\alpha$ values in experimental human endotoxaemia. ${ }^{23}$ Although suprahepatic inferior vena cava $\mathrm{TNF} \alpha$ values underestimate those in the hepatic vein, the lack of a significant difference between portal vein concentrations and either arterial or suprahepatic inferior vena cava TNF $\alpha$ values suggests that the splanchnic source of $\mathrm{TNF} \alpha$ is both hepatic and prehepatic.

Hepatic ischaemia was used in these experiments to reduce hepatic clearance, ${ }^{16}$ and led to a significantly higher TNF $\alpha$ output after mesenteric vein endotoxin injection than is seen in normal animals. This is unlikely to be due to enteric endotoxin translocation because the arterial endotoxin values and the $T N F \alpha$ endotoxaemia, animals can be tolerised with TNF $\alpha$ to withstand ordinarily fatal doses of endotoxin. ${ }^{1+151819}$ Pretreatment of baboons with anti-TNF $\alpha$ antibodies can prevent multiple organ failure and mortality after infusion of an LD100 dose of live $E$ coli.$^{13}$ These data sugges that TNF $\alpha$ is the central mediator of the toxic and lethal effects of endotoxin. Other cytokines 
concentrations in control animals subjected to hepatic ischaemic do not differ from those of the control animals in groups 1 and 2 . The source of the additional TNF $\alpha$ is not hepatic because the suprahepatic inferior vena cava values were not significantly different to arterial or portal vein concentrations. These findings indicate enhanced extrahepatic endotoxin uptake with consequently greater $\mathrm{TNF} \alpha$ secretion.

Overall endotoxin clearance in this study is not demonstrably different with either route of administration in normal animals, nor is it disturbed in the first five minutes after hepatic ischaemia. Endotoxin clearance in the rabbit is rapid, with $70 \%$ of the injected dose being cleared in the first minute. ${ }^{1}$ At 30 minutes after injection, arterial endotoxin concentrations are significantly higher in the hepatic ischaemia group, indicating a reduction in the second phase of clearance. Gross clearance is known to be an insensitive measure of hepatic clearance in experimental animals because other macrophage populations can compensate. ${ }^{24}$ Clinical estimates of gross and organ specific clearance are usually done with radiolabelled aggregated albumin or other colloids. These agents do not test Kupffer cell uptake alone, because hepatic sinusoidal endothelial cells show a significant capacity to clear such substances. ${ }^{25}$ Endotoxin is the only target substance whose primary uptake in the liver in rats is exclusively by Kupffer cells, ${ }^{+25}$ thus TNF $\alpha$ measurements after mesenteric vein injection may provide a research tool for assessing their phagocytic function in experimental animals. Radiolabelled endotoxin could be used to measure Kupffer cell clearance, but because Kupffer cells transfer ingested endotoxin rapidly to hepatocytes for prompt biliary excretion, such a technique would be less accurate in conditions of hepatocellular dysfunction or cholestasis. ${ }^{+}$

In hepatobiliary diseases associated with reduced hepatic clearance, endotoxaemia and its complications are common. ${ }^{926}$ The results of this study indicate that excessive TNF $\alpha$ secretion by extrahepatic macrophages may be implicated in the increased sensitivity to endotoxin, and this suggests a possible prophylactic role for antiTNF $\alpha$ antibodies or inhibitors of TNF $\alpha$ production such as oxpentifylline. ${ }^{132728}$ Such intervention could be of value in patients undergoing surgical relief of obstructive jaundice or liver transplantation, in whom perioperative endotoxaemia is common and related to postoperative morbidity and mortality. ${ }^{29} 30$

1 Mathison JC, Ulevitch RJ, Fletcher JR, Cochrane CG. The distribution of lipopolysaccharide in normocomplementaemic and $\mathrm{C}_{3}$ depleted rabbits and rhesus monkeys. Am Pathol 1980; 101: 245-64.

2 Yamaguchi Y, Yamaguchi $\mathrm{K}$, Babb JL, Gans $\mathrm{H}$. In vivo quantitation of the rat liver's ability to eliminate endotoxin from portal vein blood. F Reticuloendothel Soc 1982; 32:40922.
3 Rutenberg S, Skarnes R, Palmerio C, Fine J. Detoxification of endotoxin by perfusion of liver and spleen. Proc Soc Exp Biol Med 1967; 125: 455-9.

4 van Bossuyt $\mathrm{H}$, De Zanger RB, Wisse E. Cellular and subcellular distribution of injected lipopolysaccharide in rat liver and its inactivation by bile salts. F Hepatol 1988; 7: 325

5 Drivas G, James O, Wardle N. Study of reticuloendothelial phagocyte capacity in patients with cholestasis. BMF 1976 i: $1568-9$

6 Pain JA. Reticuloendothelial function in obstructive jaundice. BrF Surg 1987; 74: 1091-4.

7 Arii S, Monden K, Itai S, Sasoki T, Shibagaki M, Tobe T. The three phases of reticuloendothelial system function in rats with liver injury. F Surg Res 1988; 45: 314-9.

8 Pain JA, Bailey ME. Prevention of endotoxaemia in obstructive jaundice - a comparative study of bile salts. Hepatic Pancreatic Biliary Surg 1988; $1: 21-7$.

9 Cahill CJ, Pain JA, Bailey ME. Bile salts, endotoxin and rena function in obstructive jaundice. Surg Gyncol Obstet 1987 165: 519-22.

10 Dixon JM, Armstrong CP, Duffy SW, Elton BA, Davies GC Upper gastrointestinal bleeding. A significant complication after surgical relief of obstructive jaundice. Ann Surg 1984; 199: $271-5$

11 Lumsden $\mathrm{AB}$, Henderson JM, Kutner MH. Endotoxin levels measured by a chromogenic assay in portal, hepatic and peripheral venous blood in patients with cirrhosis. Hepatolog 1988; 8: 232-6.

12 Callery MP, Kamei T, Flye W. Kupffer cell blockade increases mortality during intra-abdominal sepsis despite improvin systemic immunity. Arch Surg 1990; 125: 36-41.

13 Tracey KJ, Fong Y, Hesse DG, Manogue KR, Lee AJ, Kuo $\mathrm{GC}$, et al. Anti-cachectin/tumour necrosis factor monoclonal antibodies prevent septic shock during lethal bacteraemia. Nature 1987; 330: 662-4

14 Mayoral JL, Schweich CJ, Dunn DL. Decreased tumour necrosis factor during the initial stages of infection correlates with survival during murine Gram-negative sepsis. Arch Surg 1990; 125; 24-8.

15 Waage A, Brandtzaeg P, Halstensen A, Kierulf P, Espevik T. The complex pattern of cytokines in serum from patients with meningococcal septic shock. F Exp Med 1989; 169: 333-8.

16 Olcay I, Kitahama A, Miller RH, Drapanas T, Trejo RA, Di Luzio NR. Reticuloendothelial dysfunction and endotoxaemia following portal vein occlusion. Surgery 1974; 75 : 64-70.

17 Flick DA, Gifford GE. Comparison of in vitro cell cytotoxic assays for tumour necrosis factor. F Immunol Methods 1984; 68: $167-75$.

18 Damas P, Reuter A, Gysen P, Demonty J, Lamy M, Franchimont $P$. Tumour necrosis factor and interleukin- 1 severe sepsis in humans. Crit Care Med 1989; 17: 975-8.

19 Fraker DL, Stovroff MC, Merino MJ, Norton JA. Tolerance to tumour necrosis factor in rats, and the relationship to endotoxin tolerance and toxicity. $\mathcal{F} E x p$ Med 1988; 168: 95105 .

20 Hesse DG, Tracey KJ, Fong Y, Manogue KR, Palladino MA, Cerami A, et al. Cytokine appearance in human endotoxaemia and primate bacteraemia. Surg Gynecol Obstet 1988; 166 : $147-53$

21 Mathison JC, Wolfson E, Ulevitch RJ. Participation of tumour necrosis factor in the mediation of Gram-negative bacterial lipopolysaccharide-induced injury in rabbits. $\mathcal{J}$ Clin Invest lipopolysaccharide-in

22 Callery MP, Kamei T, Mangino MJ, Flye W. Organ interactions in sepsis, host defense and the hepatic pulmonary axis. Arch Surg 1991; 126: 28-32.

23 Fong Y, Marano MA, Moldawer LL, Wei HE, Calvano SE, Kenney JS, et al. The acute splanchnic and peripheral tissue metabolic response to endotoxin in humans. $\mathcal{F}$ Clin Invest 1990; 85: 1896-904.

24 Katz S, Grosfeld JL, Gross, Jubran A, Adams J, Grefint OW, et al. Impaired bacterial clearance and trapping in obstructive jaundice. Ann Surg 1984; 199: 14-20.

25 Praaning-van Dalen D, Brouwer A, Knook DL. Clearance capacity of rat liver Kupffer, endothelial and parenchymal cells. Gastroenterology 1981; 81: 1036-44

26 Wait RB, Kahng KU. Renal failure complicating obstructive jaundice. Am $\mathcal{F}$ Surg 1989; 157: 256-63.

27 Exley AR, Cohen J, Buurman W, Owen R, Hanson G, Lumley J, et al. Monoclonal antibody to tumour necrosis fumley J, et al. Monoclonal antibody to tumour nect in severe septic shock. Lancet 1990; i: 1275-7.

28 Zabel P, Wolter DT, Schonharting M, Schade UF. Oxpentifylline in endotoxaemia. Lancet 1989; ii: 1474-7.

29 Yokoyama I, Todo S, Miyata T, Selby R, Tzakis AG, Starzl TE. Endotoxaemia and human liver transplantation. Transplant Proc 1989; 21: 3833-4.

30 Ingoldy CJ, McPherson GAD, Blumgart LH. Endotoxaemia in human obstructive jaundice. Effects of polymixin B. Am F Surg 1984; 147: 766-71. 